\title{
TCMGIS-II based prediction of medicinal plant distribution for conservation planning: a case study of Rheum tanguticum
}

Hua $\mathrm{Yu}^{1 \dagger}$, Caixiang $\mathrm{Xie}^{1 \dagger}$, Jingyuan Song ${ }^{1}$, Yingqun Zhou ${ }^{1,3}$, Shilin Chen ${ }^{1,2^{*}}$

\begin{abstract}
Background: Many medicinal plants are increasingly endangered due to overexploitation and habitat destruction. To provide reliable references for conservation planning and regional management, this study focuses on largescale distribution prediction of Rheum tanguticum Maxim. ex Balf (Dahuang).

Methods: Native habitats were determined by specimen examination. An improved version of GIS-based program for the distribution prediction of traditional Chinese medicine (TCMGIS-II) was employed to integrate national geographic, climate and soil type databases of China. Grid-based distance analysis of climate factors was based on the Mikowski distance and the analysis of soil types was based on grade division. The database of resource survey was employed to assess the reliability of prediction result.
\end{abstract}

Results: A total of 660 counties of 17 provinces in China, covering a land area of $3.63 \times 10^{6} \mathrm{~km}^{2}$, shared similar ecological factors with those of native habitats appropriate for $R$. tanguticum growth.

Conclusion: TCMGIS-II modeling found the potential habitats of target medicinal plants for their conservation planning. This technology is useful in conservation planning and regional management of medicinal plant resources.

\section{Background}

More than one-tenth of plant species are used in drugs and health products [1]. The demand for herbal drugs and health products is steadily growing [2]. Thus, many medicinal herbs are threatened by overexploitation, habitat destruction and lack of proper cultivation practices. Some wild species are disappearing at alarming rates [3,4]. Rheum tanguticum Maxim. ex Balf (Dahuang) is one of those species. R. tanguticum belongs to the family Polygonaceae and is a high-altitude perennial herb sensitive to high temperature, mainly found in the alpine regions of temperate and subtropical Asia, especially in Southwest and Northwest China (e.g. Sichuan, Gansu and Qinghai) [5,6]. As a source for rhubarb according to the Chinese Pharmacopoeia and a purgative and anti-inflammatory agent [7],

\footnotetext{
* Correspondence: slchen@implad.ac.cn

† Contributed equally

'Institute of Medicinal Plant Development, Chinese Academy of Medical

Sciences, Peking Union Medical College, Beijing 100193, China

Full list of author information is available at the end of the article
}

R. tanguticum has been overexploited, suffering from replant diseases, inadequate seed dispersal, low reproductive efficiency and narrow distribution and habitat fragmentation, leading to its declines in the wild resources $[6,8]$.

In-situ conservation, which considered as the method of conserving endangered species in their wild habitats, is promising in protecting indigenous species and maintaining natural communities along with their intricate network of relationships [9]. As habitat degradation and destruction is increasing, ex-situ conservation regarded as the process of cultivating and naturalizing endangered species outside of their original habitats, has become a practical alternative [10-12], especially for those overexploited and endangered medicinal plants with slow growth, small abundance and replant diseases $[10,13]$, e.g. Paris species in family Trilliaceae and Panax species in family Araliaceae [14]. Ex-situ cultivation becomes an immediate action to sustain medicinal plant resources $[11,12]$. 
Understanding the geographical distribution of plant species is essential for their ex-situ conservation activities $[1,15]$. Although many plant species can be successfully introduced, cultivated and naturalized in a wide range of habitats across countries and continents [16], their growth and distribution in different habitats are based on local indicators [17], e.g. soil properties, climate conditions and environmental features [18]. Aguilar-Stoen and Moe (2007) found that many medicinal plants thriving in harsh habitats and disturbed areas are of high medicinal efficacy because rocky and dry habitats stimulate their secondary metabolites [19]. Many plants are only found in places where the habitat is congruent with their growth [18], e.g. the propagation and quality of Banksia serrata varied among habitats [20]. Variations in growth and metabolites of medicinal plants among niches make $e x$-situ conservation habitat-specific.

Geographical prediction of plant distribution is important to resource conservation planning and regional management decisions [21]. Geographic Information System (GIS) is useful in predicting the spatial distribution of target species [22]. GIS assesses multiple interdependent abiotic factors, e.g. solar radiation, air temperature, precipitation and soil properties [23], affecting plant distribution, models the environmental niches of target plants [24] and refines their distribution maps for conservation planning [25].

A GIS-based computer program (TCMGIS-I) was developed specially for the distribution prediction of Chinese medicine $(\mathrm{CM})[25,26]$. Integrating national geographic, climate and soil type databases of China, TCMGIS-I was able to determine the impacts of environmental gradients and predict the large-scale distribution of target medicinal plants [26]. Tests with some common medicinal plants (e.g. Panax ginseng, Panax quinquefolium, Glycyrrhiza uralensis and Artemisia annua) demonstrated that TCMGIS-I prediction was consistent with the actual plants' distribution patterns [27-30].

While TCMGIS-I captures data from literature, TCMGIS-II can perform more precise variable extraction from the native habitats of target medicinal plants. Factors such as elevation, air temperature, solar radiation, precipitation and soil properties are considered by TCMGIS-II. Moreover, TCMGIS-II defines the native habitats of a target plant through specimen examination and extracts the target variables of native habitats from its databases.

The present study aims to determine (1) the most important ecological factor(s) on the distribution of $R$. tanguticum, (2) whether the prediction results are consistent with survey data and (3) the implications of the prediction results for the conservation planning of $R$. tanguticum.

\section{Methods}

\section{Database descriptions}

Based on a spatially referenced GIS model, TCMGIS-II integrated four databases, including the national geographic, climate and soil type databases of China which were used to generate distribution models and the database of resource survey which was used to assess the quality of a model.

The geographic database of China was a digital chart (scale 1:1,000,000) at national, provincial, regional and county levels, including a series of vector maps of layers, i.e. manuals on roads, contours, geology and administrative boundaries, with all points covered with a geographic coordinate system (e.g. latitude, longitude and elevation).

The climate database of China was derived from the national climate data coving from the period of 1971 to 2000 extracted from the climate records of the state meteorological administration of China. The database included climate attributes related to plant growth, e.g. sunshine duration, relative humidity, annual precipitation, accumulated temperature, mean annual temperature, mean March temperature, annual maximum/minimum temperature and annual mean maximum/minimum temperature. The climate data were available in GIS along with data of latitude, longitude and elevation.

The soil type database of China covered a total of 2,444 counties, containing a series of vector soil maps (scale 1:1,000,000) and soil attributes and mapping unit boundaries. The soil data were classified into 12 orders, 29 suborders, 61 groups, 235 subgroups and 909 families as the basic elements of the map layers [31].

The database of resource survey was generated with the third national resource survey of CM in China, covering a total of 11,118 plant species in 2312 genera of 385 families, including 298 fungi, 114 algae, 43 mosses, 55 lichens, 455 ferns, 126 gymnosperms and 10,027 angiosperms [32], as well as descriptions on the abundance and distribution patterns of 138 rare and endangered medicinal plants, 126 of which were converted into digital charts (scale 1:1,000,000).

\section{Model descriptions}

TCMGIS-II identified, analyzed and displayed geographically referenced information, using two major data models (i.e. raster and vector). Raster model in $1.0 \times$ $1.0 \mathrm{~km}^{2}$ grids detected the grids sharing similar ecological factors with those of the native habitats of a target medicinal plant. Vector model stacked the layers of those factors to determine the distribution areas and ranges.

\section{Extraction of ecological factors from native habitats}

Based on 75 type specimens of wild $R$. tanguticum from Chinese Virtual Herbarium, we set up 206 plots 


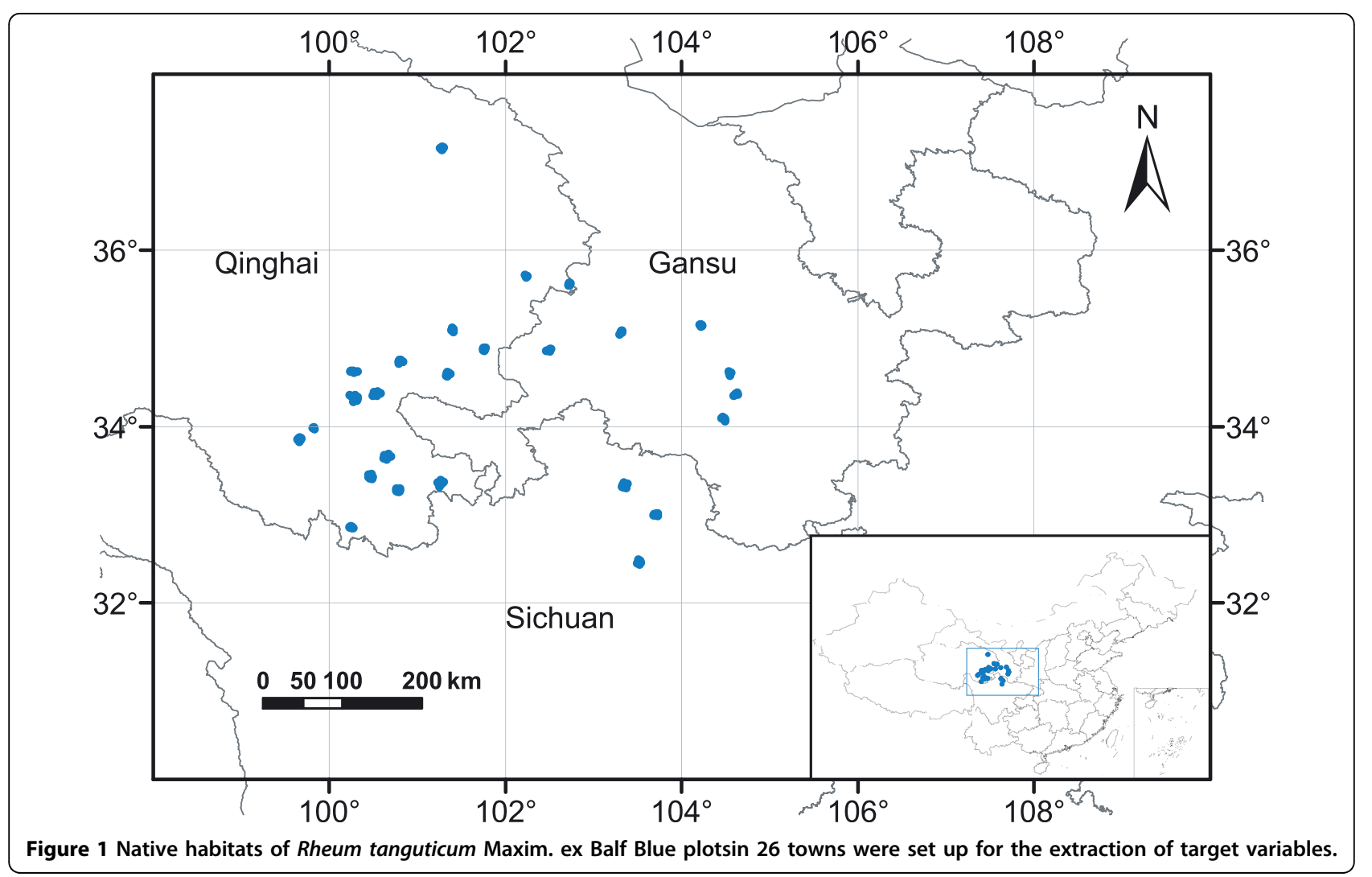

in 26 towns of nine counties in the provinces of Gansu, Qinghai and Sichuan (Figure 1), the native habitats of $R$. tanguticum. The ecological factors of the plots were extracted by TCMGIS-II, including elevation, soil type, sunshine duration, relative humidity, annual precipitation, accumulated temperature, mean annual temperature, mean March temperature, annual maximum/minimum temperature and annual mean maximum/minimum temperature (Table 1). The variables extracted from the native habitats were set as target variables for distance analysis with grids.

Table 1 Variables extracted from the native habitats of Rheum tanguticum Maxim. ex Balf based on TCMGIS-II combined geographic, climate and soil type databases

\begin{tabular}{|c|c|c|c|c|c|}
\hline Variable & Unit & Range & Mean \pm SE & $F$-value & $C_{v}(\%)$ \\
\hline Elevation & $\mathrm{m}$ & 1980,4550 & $3630 \pm 44$ & $191.2^{* * *}$ & 17.4 \\
\hline Relative humidity & $\%$ & $54.8,69.0$ & $63.7 \pm 2.2$ & $219.3^{* * *}$ & 49.6 \\
\hline Sunshine duration & $\mathrm{hr} / \mathrm{yr}$ & 1897,2704 & $2450 \pm 13$ & $301.7^{* * *}$ & 7.6 \\
\hline Annual precipitation & $\mathrm{mm}$ & 331,839 & $574 \pm 7$ & $233.2^{* * *}$ & 17.5 \\
\hline Accumulated temperature & ${ }^{\circ} \mathrm{C}$ & 3193,22451 & $9517 \pm 951$ & $277.1^{* * *}$ & 143.4 \\
\hline Mean annual temperature & ${ }^{\circ} \mathrm{C}$ & $5.1,13.1$ & $8.6 \pm 0.1$ & $92.6^{* * *}$ & 16.7 \\
\hline Mean March temperature & ${ }^{\circ} \mathrm{C}$ & $-8.0,-2.0$ & $-4.5 \pm 0.2$ & $42.3^{* * *}$ & 63.8 \\
\hline Minimum temperature & ${ }^{\circ} \mathrm{C}$ & $-24.8,-10.6$ & $-19.1 \pm 0.2$ & $165.8^{* * *}$ & 15.0 \\
\hline Maximum temperature & ${ }^{\circ} \mathrm{C}$ & $12.9,24.4$ & $17.2 \pm 0.2$ & $119.5^{* * *}$ & 16.7 \\
\hline Mean minimum temperature & ${ }^{\circ} \mathrm{C}$ & $-15.6,-5.1$ & $-11.2 \pm 0.2$ & $129.8^{* * *}$ & 25.6 \\
\hline Mean maximum temperature & ${ }^{\circ} \mathrm{C}$ & $6.0,18.2$ & $10.4 \pm 0.2$ & $103.3^{* * *}$ & 27.6 \\
\hline Soil type* & $\mathrm{pH}$ & $5.9,8.5$ & $6.8 \pm 0.1$ & $112.4^{* * *}$ & 21.1 \\
\hline
\end{tabular}

* Soil type was assigned according to soil grade division in TCMGIS-II program.

Values of $\mathrm{pH}$ were employed as an indicator of soil types for statistical analysis.

$F$-value indicates the difference in target variable extracted from different native habitats $\left({ }^{* *} P<0.001,{ }^{* *} P<0.01\right.$, and $\left.{ }^{*} P<0.05\right)$.

SE: standard error of means

$C_{v}$ : coefficient of variation 


\section{Data normalization and distance analysis}

As there were variations in factors (e.g. climate factors and soil type), TCMGIS-II normalized data by joining the mean absolute deviation of each pair of factors. To determine the similarity rate between grids and target variables from native habitats, we conducted distance measurement based on grid-based analysis. Distance analysis of soil was conducted according to grade division, while the distance analysis of elevation and climate factors was conducted based on Mikowski distance [33], in TCMGIS-II as follows:

$$
d_{i j}(q)=\left(\sum_{i=1}^{n}\left|x_{i j}-y_{i j}\right|^{q}\right)^{1 / q}
$$

Where $x_{i j}$ is the grid value and $y_{i j}$ is a target variable.

When $q=1$, it is Manhattan distance.

When $q=2$, it is Euclidean distance.

Long distance indicates low similarity rates while short distance indicates high similarity rates.

\section{Spatial distribution division and model quality assessment}

Division on spatial distribution of $R$. tanguticum was established according to the grid-based clustering. The areas sharing similar ecological factors with those of native habitats were favorable for $R$. tanguticum distribution. The spatially predicted areas were divided into three types, namely the favorable (with similarity rate $\geq 95 \%$ ), suitable (with similarity rate $90-95 \%$ ), and slightly appropriate (with similarity rate $<90 \%$ ) for $R$. tanguticum distribution.

To assess the reliability of the spatial prediction on $R$. tanguticum distribution, we employed the database of resource survey as a measure. The overlapping part between distribution range predicted by TCMGIS-II and that recorded by resource survey indicates the congruency, the part with prediction result without survey data suggests the potential distribution of $R$. tanguticum, and the rest part with survey data beyond prediction result indicates the contradiction between prediction result and survey data.

\section{Statistical analyses}

To detect the variations in the abiotic factors (e.g. elevation, air temperature, solar radiation, precipitation and soil properties in Table 1) of different native habitats, we employed the coefficient of variation $\left(C_{v}\right)$ as a measure [34]. It is defined as the follows:

$$
C_{v}=\frac{\sigma}{\mu} \times 100 \%
$$

Where $\sigma$ is the standard deviation and $\mu$ is the mean.

We employed one-way analysis of variance (one-way ANOVA) to analyze the differences in the abiotic factors responding to different native habitats (Table 1), and principal components analysis (PCA) to evaluate the contributions of the abiotic factors to $R$. tanguticum distribution (Figure 2).








\section{Results}

\section{Target variables extracted from native habitats}

TCMGIS-II extracted the target variables from 206 plots in the native habitats of $R$. tanguticum (Figure 1, Table 1 ). The results showed that the target variables varied significantly among different native habitats (Table $1, P$ $<0.001$ ), with coefficient of variation ranging from $7.6 \%$ in sunshine duration to $143.4 \%$ in accumulated temperature, and the native habitats exhibited high elevation and abundant sunshine with moderate cool and dry climate in mild acid and basic soils (Table 1). Using PCA, we extracted two principal components (PCs) which accounted for $93.8 \%$ of the contribution of target variables in terms of $R$. tanguticum distribution (Figure $2)$. The $\mathrm{PC}_{1}\left(\mathrm{PC}_{1}=60.3 \%\right)$ was mainly related to temperatures (e.g. annual maximum, annual mean 
maximum, mean annual and acuminated temperatures) and the $\mathrm{PC}_{2}\left(\mathrm{PC}_{2}=33.5 \%\right)$ was mainly contributed by annual precipitation and relative humidity. However, elevation and annual precipitation were negatively correlated to $\mathrm{PC}_{1}$, and sunshine duration was negatively contributed to $\mathrm{PC}_{2}$ (Figure 2).

\section{Prediction result of potential distributions}

The spatial distribution of $R$. tanguticum was established by overlapping the layers of those geographic, climate and soil factors based on distance analyses. The scope of favorable areas (with similarity rate $\geq 95 \%$ ) was within $80^{\circ} 26^{\prime}-131^{\circ} 21^{\prime} \mathrm{E}$ and $27^{\circ} 03^{\prime}-45^{\circ} 21^{\prime} \mathrm{N}$ (Figure 3a), covering 395 counties in 13 provinces such as Xizang (Tibet), Sichuan, Qinghai and Gansu in China with a land area of $7.46 \times 10^{5} \mathrm{~km}^{2}$ (Figure 4). The scope of suitable areas (similarity rate $90-95 \%$ ) was within $74^{\circ} 05^{\prime}-132^{\circ} 24^{\prime} \mathrm{E}$ and $26^{\circ} 38^{\prime}-47^{\circ} 22^{\prime} \mathrm{N}$ (Figure 3b), covering 396 counties in 17 provinces with a land area of $2.89 \times 10^{6} \mathrm{~km}^{2}$ (Figure 4). In addition to 131 counties of both favorable and suitable ranges, 660 counties were tested suitable for $R$. tanguticum cultivation (similarity rate $290 \%$ ).

\section{Comparison between prediction results and survey data}

Rhubarb distributed in 101 counties in Sichuan, Xizang and Qinghai provinces within the range of $89^{\circ} 25^{\prime}-107^{\circ}$ $16^{\prime} \mathrm{E}$ and $27^{\circ} 05^{\prime}-39^{\circ} 06^{\prime} \mathrm{N}$ (Figure 5). Comparison between the distribution counties predicted by TCMGIS-II modeling and recorded by resource survey demonstrated the high quality of prediction result (Figure 6). Specifically, a total of 663 counties were listed by the survey data and prediction result, with $97.0 \%$ of survey data covered by the prediction result of TCMGIS-II analysis. The majority $(85.2 \%)$ of prediction data corresponded to no survey data and $2.9 \%$ of survey data did not overlap with the prediction results.

\section{Discussion}

The ecological factors from native habitats suggest that $R$. tanguticum grows at high plateau (e.g. alpine meadow, grassland and shrub) with cool climate, abundant sunshine, moderate precipitation and basic soils (e.g. humus-rich loam and sandy loam) and that its distribution is mainly influenced by temperature (e.g. annual maximum, mean annual and acuminated temperatures), annual precipitation and relative humidity. The prediction results by TCMGIS-II confirmed the distribution data.

Many plant species have evolved to be habitat-specific and sensitive to environmental conditions [35], and those growing at the sites congruent with their native habitats are the most potent [17]. For example, $R$. tanguticum from Gansu and Qinghai is recorded as a source of rhubarb in the Chinese Pharmacopoeia due to its high potency $[7,32]$. The present study found that a large portion of predictive distributions were beyond what survey data covered (e.g. Xinjiang, Inner-Mongolia and Shanxi provinces), agreeing with the notion that prediction of distribution may help locate habitats for conservation [24,36], giving insights into the discovery of potential habitats for $R$. tanguticum cultivation.

Interestingly, a small portion of survey data does not overlap with prediction result, e.g. Muli in Sichuan and Zhongdian in Yunnan. According to the Chinese Pharmacopoeia, there are three prescribed sources (i.e. $R$. tanguticum, $R$. palmatum and $R$. officinale) for rhubarb [7]. The survey data cover the three Rheum species. On the other hand, the databases of TCMGIS-II include

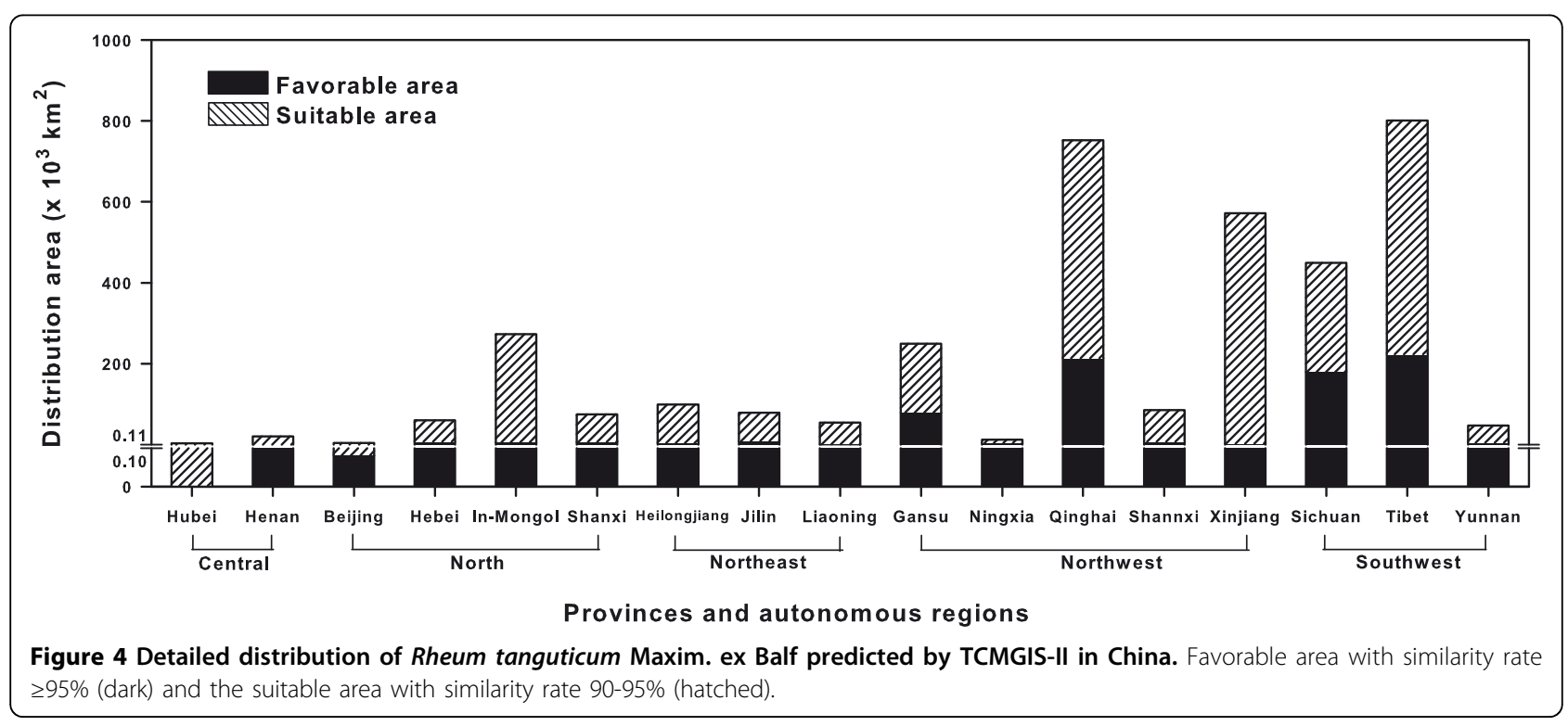




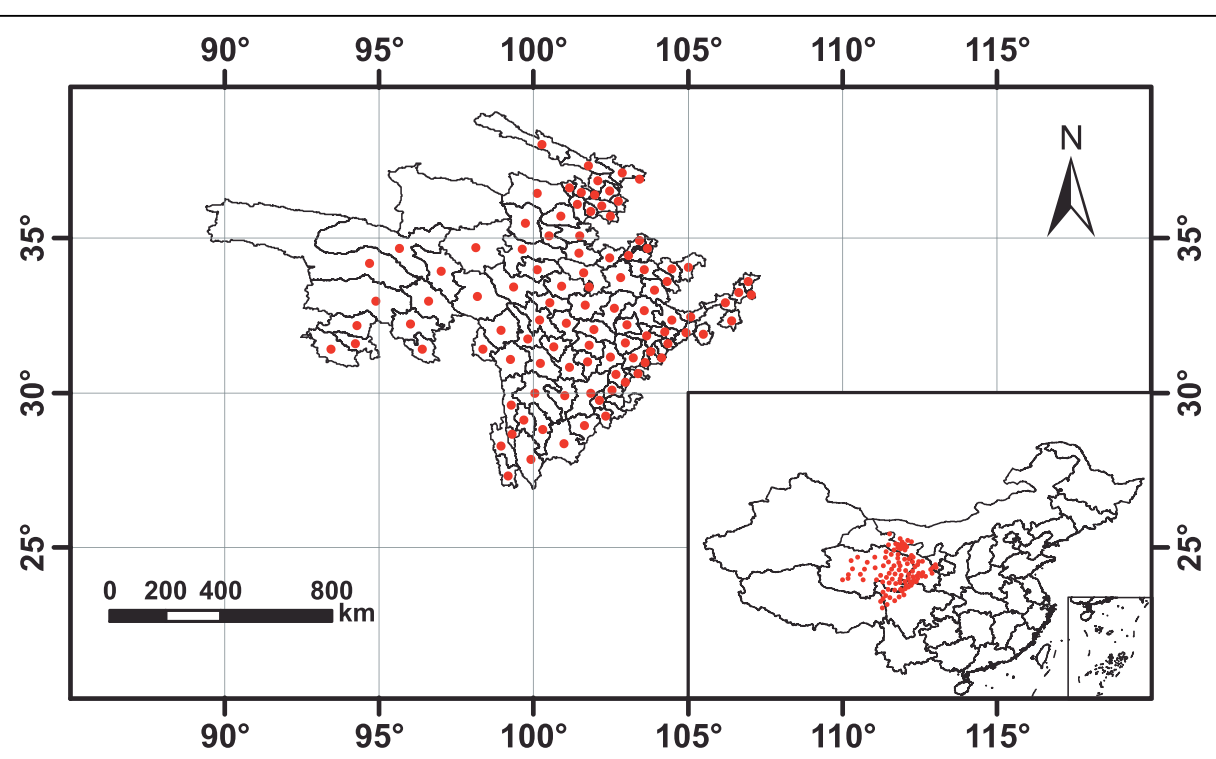

Figure 5 Distribution map of rhubarb generated based on the database of resource survey. The red dots show that there existed the wild resources of $R$. tanguticum in the counties. Longitude $\left({ }^{\circ} \mathrm{E}\right)$ and latitude $\left({ }^{\circ} \mathrm{N}\right)$ are given.

many abiotic factors (e.g. topographic features, climate conditions and soil properties) but not the effects of dynamic biotic interactions and species-specific features on a large scale. Many plant species are sensitive to both abiotic and biotic factors, such as competitor plants and symbiotic species $[37,38]$.

In the present study, the distribution of $R$. tanguticum predicted by TCMGIS-II program was confirmed by the resource survey data. We expect that the TCMGIS-II modeling is useful in conservation planning and regional management for the threatened medicinal plants [19]. Both conservation and sustainable utilization of medicinal plants require robust large-scale assessment of their distribution and regionalization [1]. Lack of data and limit of model validity are barriers for the studies on distribution of medicinal plants on a large scale [39]. Thus, more data and model verification are necessary for further studies and GIS developments.

\section{Conclusion}

TCMGIS-II program was confirmed to be useful in the discovery of potential habitats congruent with the native habitats of target medicinal plants. This technology provides reliable references for the conservation planning and regional management of endangered and threatened medicinal plant resources.



Figure 6 Comparison between the distribution counties of Rheum tanguticum Maxim. ex Balfpredicted by TCMGIS-II and recorded by the survey data. Latticed: the counties of survey data in prediction result. Left hatched: those of prediction results without survey data. Right hatched: those of survey data beyond prediction results. The percentage and number of counties in each part are given. 


\section{Abbreviations}

CM: Chinese medicine; GIS: geographic information system; TCMGIS-I: a GISbased program for the distribution prediction of traditional Chinese medicine; TCMGIS-II: the improved version of TCMGIS-I program; $C_{v}$ : coefficient of variation; One-way ANOVA: one-way analysis of variance; PCA: principal components analysis; PC: a principal component; SE: standard error

\section{Acknowledgements}

We thank Prof Yulin Lin for his help with specimen identification, Prof Chengzhong Sun and Prof Runhuai Zhao for their constructive comments on TCMGIS-II modeling, Prof Christine Leon and Mr Chun Un for their assistance in polishing the manuscript. This study was supported by the National Key Technology R\&D Programs in the $11^{\text {th }}$ Five-year Plan of China (2006BAl09B02, 2006BAl21B07) and China Post-doctoral Foundation (20090450329)

\section{Author details}

'Institute of Medicinal Plant Development, Chinese Academy of Medical Sciences, Peking Union Medical College, Beijing 100193, China. ${ }^{2}$ Hubei University of Chinese Medicine, Wuhan 430065, China. ${ }^{3}$ Technology Development Centre, China National Group Corporation of Traditional and Herbal Medicine, Beijing 100094, China.

\section{Authors' contributions}

SC designed the study and revised the manuscript. HY examined the specimens and wrote the manuscript. CX conducted the TCMGIS-II analysis, $\mathrm{JS}$ and $\mathrm{YZ}$ helped specimen collection and statistical analysis. All authors revised the manuscript. All authors read and approved the final version of the manuscript.

\section{Competing interests}

The authors declare that they have no competing interests.

Received: 6 November 2009 Accepted: 25 August 2010 Published: 25 August 2010

\section{References}

1. Russell-Smith J, Karunaratne NS, Mahindapala R: Rapid inventory of wild medicinal plant populations in Sri Lanka. Biol Conserv 2006, 132:22-32.

2. Hamilton AC: Medicinal plants, conservation and livelihoods. Biodivers Conserv 2004, 13:1477-1517.

3. Mentreddy SR: Review - medicinal plant species with potential antidiabetic properties. J Sci Food Agric 2007, 87:743-750.

4. Reddy KN, Reddy CS: First red list of medicinal plants of Andhra Pradesh, India - conservation assessment and management planning. Ethnobot Lealf 2008, 12:103-107.

5. Wu Z, Raven PH, Garden MB: Flora of China Beijing: Science Press 1994.

6. Wang $X \mathrm{M}$, Ren $\mathrm{Y}$ : Rheum tanguticum, an endangered medicinal plant endemic to China. J Med Plants Res 2009, 3:1195-1203.

7. Chinese Pharmacopoeia Committee: Pharmacopoeia of the People's Republic of China Beijing: Chinese Medical Technological Press 2010.

8. Li M, Li LX, Liu Y: Study survey on rhubarb in recent years. World Sci Tech/ Mod Trad Chin Med 2006, 8:34-39.

9. Meilleur BA, Hodgkin T: In situ conservation of crop wild relatives: status and trends. Biodivers Conserv 2004, 13:663-684.

10. Shinwari ZK, Gilani SS: Sustainable harvest of medicinal plants at Bulashbar Nullah, Astore (Northern Pakistan). J Ethnopharmacol 2003, 84:289-298.

11. Barazani O, Perevolotsky A, Hadas R: A problem of the rich: prioritizing local plant genetic resources for ex situ conservation in Israel. Biol Conserv 2008, 141:596-600.

12. Rita A, Silvano M: Ex situ conservation and rare plants propagation in the Lecce botanical garden: reproductive biology problems. Caryologia 2006, 59:345-349.

13. Chen SL, Wei JH, Huang LF, Guo BL, Xiao PG: Probing into the theory and practice of wild medicinal materials tending. China J Chin Mater Med 2004, 29:1123-1126.
14. Long CL, Li H, Ouyang ZQ, Yang XY, Li Q, Trangmar B: Strategies for agrobiodiversity conservation and promotion: a case from Yunnan, China. Biodivers Conserv 2003, 12:1145-1156.

15. Williams JN, Seo CW, Thorne J, Nelson JK, Erwin S, O'Brien JM, Schwartz MW: Using species distribution models to predict new occurrences for rare plants. Divers Distrib 2009, 15:565-576.

16. Ginnett TF, Demment MW: Sexual segregation by Masai giraffes at two spatial scales. Afr J Ecol 1999, 37:93-106.

17. Ghimire SK, McKey D, Aumeeruddy-Thomas Y: Heterogeneity in ethnoecological knowledge and management of medicinal plants in the Himalayas of Nepal: implications for conservation. Ecol Soc 2004, 9:9-24.

18. Pulliam HR: On the relationship between niche and distribution. Ecol Lett 2000, 3:349-361.

19. Aguilar-Stoen M, Moe SR: Medicinal plant conservation and management: distribution of wild and cultivated species in eight countries. Biodivers Conserv 2007, 16:1973-1981.

20. Whelan RJ, De Jong NH, Von der Burg S: Variation in bradyspory and seedling recruitment without fire among populations of Banksia serrata (Proteaceae). Aust J Ecol 1998, 23:121-128.

21. Rodriguez JP, Brotons L, Bustamante J, Seoane J: The application of predictive modelling of species distribution to biodiversity conservation. Divers Distrib 2007, 13:243-251.

22. Guisan A, Thuiller W: Predicting species distribution: offering more than simple habitat models. Ecol Lett 2005, 8:993-1009.

23. Arundel ST: Using spatial models to establish climatic limiters of plant species' distributions. Ecol Model 2005, 182:159-181.

24. Chefaoui RM, Hortal J, Lobo JM: Potential distribution modelling, niche characterization and conservation status assessment using GIS tools: a case study of Iberian Copris species. Biol Conserv 2005, 122:327-338.

25. Chen SL, Suo FM, Han JP, Xie CX, Yao H, Li XW, Li Y, Wei JH: Analysis on ecological suitability and regionalization of traditional Chinese medicinal materials. Chin Trad Herb Drugs 2007, 38:481-487.

26. Sun CZ, Liu ZQ, Chen SL, Wei JH, Zhao RH, Wang JY, Zhou YQ: Design and realization of traditional Chinese medicine adaptability analyzing system based on GIS. World Sci Tech/Mod Trad Chin Med 2006, 8:112-117.

27. Wang Y, Wei JH, Chen SL, Sun CZ, Zhao RH, Liu ZQ, Xiao XH, Wang JY, Zhou YQ: Analysis of Panax Ginseng's producing area based on TCMGIS-I. Asia Pac Trad Med 2006, 6:73-78.

28. Chen SL, Zhou YQ, Xie CX, Zhao RH, Sun CZ, Wei JH, Liu ZQ, Gao WW: Suitability evaluation of Panax quinquefolium's producing area based on TCMGIS-I. Zhongguo Zhong Yao Za Zhi 2008, 33:741-745.

29. Wang JY, Zhao RH, Sun CZ, Chen SL, Liu ZQ, Wei JH, Xiao XH, Zhou YQ: Suitability evaluation of Glycyrrhiza uralensis Fisch.'s distributive area based on TCMGIS-I. Mod Chin Med 2006, 8:4-8.

30. Huang LF, Xie CX, Duan BZ, Chen SL: Mapping the potential distribution of high artemisinin-yielding Artemisia annua L. (Qinghao) in China with a geographic information system. Chin Med 2010, 5:18-25,

31. Shi XZ, Yu DS, Warner ED, Pan XZ, Petersen GW, Gong ZG, Weindorf DC: Soil database of 1: 1,000,000 digital soil survey and reference system of the Chinese genetic soil classification system. Soil Sur Horiz 2004, 45:129-136.

32. China National Group Corporation of Traditional and Herbal Medicine: Regionalization of Traditional Chinese Medicine Beijing: Science Press 1995.

33. Warren LT: Clustering of time series data - a survey. Pattern Recognit 2005, 38:1857-1874.

34. Bedeian AW, Mossholder KW: On the use of the coefficient of variation as a measure of diversity. Organ Res Methods 2000, 3:285-297.

35. Heinanen $S$, von Numers M: Modelling species distribution in complex environments: an evaluation of predictive ability and reliability in five shorebird species. Divers Distrib 2009, 15:266-279.

36. Chen SL, Xie CX, Yao H, Song JY, Sun C: Methodological innovations in traditional Chinese medicine resources. World Sci Tech/Mod Trad Chin Med 2008, 10:1-9.

37. Kala CP: Status and conservation of rare and endangered medicinal plants in the Indian trans-Himalaya. Biol Conserv 2000, 93:371-379.

38. Dhyani PP, Kala CP: Current research on medicinal plants: five lesser known but valuable aspects. Curr Sci 2005, 88:335. 
39. Thuiller W, Albert C, Araujo MB, Berry PM, Cabeza M, Guisan A, Hickler T, Midgely GF, Paterson J, Schurr FM, Sykes MT, Zimmermann NE: Predicting global change impacts on plant species distributions: future challenges. Perspect Plant Ecol Evol Syst 2008, 9:137-152.

doi:10.1186/1749-8546-5-31

Cite this article as: Yu et al:: TCMGIS-II based prediction of medicinal plant distribution for conservation planning: a case study of Rheum tanguticum. Chinese Medicine 2010 5:31.

Submit your next manuscript to BioMed Central and take full advantage of:

- Convenient online submission

- Thorough peer review

- No space constraints or color figure charges

- Immediate publication on acceptance

- Inclusion in PubMed, CAS, Scopus and Google Scholar

- Research which is freely available for redistribution

Submit your manuscript at www.biomedcentral.com/submit 